\title{
Study on the Design and Structure of mid-infrared InGaAsSb quantum well laser
}

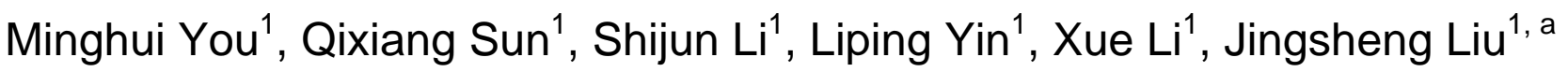 \\ ${ }^{1}$ Jilin Agricultural University, Changchun 130118, Jilin, China \\ amhyou000@163.com
}

Keywords: mid-infrared; $2 \mu$; quantum well laser.

\begin{abstract}
InGaAsSb/AlGaAsSb quantum well laser with AlGaAsSb as barrier layer and InGaAsSb as potential well layer. The composition and strain of the material have an important influence on the energy level position and band structure of the quantum well, which affects the performance of the laser. In this paper, we mainly study the materials and devices of semiconductor laser above $2 \mu \mathrm{m}$.
\end{abstract}

\section{Introduction}

$2-5 \mu \mathrm{m}$ for applications including chemical sensing for pollution monitoring and industrial process control, as well as material processing, commonincluding; optical gas sensing and environmental monitoring, free-space optical communications, infrared countermeasures, clean energy generation, biomedical and thermal imaging. For example, the mid-infrared contains the fundamental fingerprint absorption bands of a number of pollutant and toxic gases and liquids; methane $(3.3 \mu \mathrm{m}), \mathrm{CO}_{2}$ $(4.6 \mu \mathrm{m}), \mathrm{CO}(4.2 \mu \mathrm{m}), \mathrm{NO}_{\mathrm{x}}(6.5 \mu \mathrm{m})$ and $\mathrm{SO}_{\mathrm{x}}(7.3 \mu \mathrm{m})$ require accurate, in situ multi-component monitoring in a variety of different situations (e.g. oil-rigs, coal mines, landfill sites,car exhausts) and in concentrations, ranging from ppb to almost $100 \%$. The mid-infrared is very attractive for the development of sensitive optical sensor instrumentation.

The Infrared band of $2-5 \mu \mathrm{m}$ semiconductor materials mainly antimony research. However, there is an immiscible region in the antimonide multicomponent alloy, especially the carrier absorption is a serious problem, which will seriously affect the preparation process and performance of the laser, as well as the practical application of the band semiconductor lasers. $2 \mu \mathrm{m} \mathrm{InGaAsSb} / \mathrm{AlGaAsSb}$ quantum well laser with AlGaAsSb as barrier layer and InGaAsSb as potential well layer. The composition and strain of the material have an important influence on the energy level position and band structure of the quantum well, which affects the performance of the laser. In this thesis, we mainly study the materials and devices of semiconductor laser above $2 \mu \mathrm{m}$.

\section{Experiment}

InGaAsSb / AlGaAsSb multi-quantum-well lasers were grown by solid-state source molecular beam epitaxy (SSMBE). In order to effectively reduce the influence of the high Al composition limiting layer on the quantum well region, the $\mathrm{Al}$ composition and the graded-graded doping design and growth are adopted. As an example of the n-type confinement layer, the Al composition $\mathrm{x}$ is changed from 0.9 to 0.7 by first growing the $0.7 \mathrm{~m}$ thickness. The doping concentration was changed from $3 \times 10^{18} \mathrm{~cm}^{-3}$ to $1 \times 10^{18} \mathrm{~cm}^{-3}$. The Al composition $\mathrm{x}$ changed from 0.7 to 0.35 and the doping concentration varied from $1 \times 10^{18} \mathrm{~cm}^{-3}$ to $5 \times 10^{17} \mathrm{~cm}^{-3}$. At the same time, in order to reduce the In composition of the quantum well layer caused by the material into the immiscible area and reduce the strain caused by mismatch and other negative factors, the active barrier layer using a low In composition incorporation of the design, Can effectively improve the light-emitting area of the well quality, but also effectively improve the quality of the quantum well and the wavelength of light. Specific structure as shown in Table 1. Fig. 1 shows the energy band structure of 3QWs lasers. 
Table 1 InGaAsSb / AlGaAsSb multiple quantum well lasers structure

\begin{tabular}{|c|c|c|c|}
\hline Materials & Thickness(nm) & Doped & $\left(\mathrm{cm}^{-3}\right)$ \\
\hline $\mathrm{GaSb}$ & 300 & $\mathrm{P}+$ & $1.0 \times 10^{19}$ \\
\hline $\mathrm{Al}_{\mathrm{x}} \mathrm{Ga}_{1-\mathrm{x}} \mathrm{As}_{0.07} \mathrm{Sb}_{0.93}$ Clad. $\mathrm{x}=0.35-0.7$ & 1200 & $\mathrm{p}$ & $1 \times 10^{18}$ \\
\hline \multirow[t]{2}{*}{$0.7-0.9$} & & \multicolumn{2}{|r|}{$\rightarrow 3 \times 10^{18}$} \\
\hline & & & $\rightarrow 5.0 \times 10^{18}$ \\
\hline $\mathrm{Al}_{0.35} \mathrm{Ga}_{0.65} \mathrm{As}_{0.02} \mathrm{Sb}_{0.98}$ Wav. & 400 & undoped & \\
\hline $\mathrm{In}_{0.1} \mathrm{Al}_{0.25} \mathrm{Ga}_{0.65} \mathrm{As}_{0.02} \mathrm{Sb}_{0.98} /$ & 3/4/5 QWs & undoped & \\
\hline \multicolumn{4}{|l|}{$\mathrm{In}_{0.35} \mathrm{Ga}_{0.65} \mathrm{As}_{0.02} \mathrm{Sb}_{0.98} \mathrm{QWs}$} \\
\hline $\mathrm{Al}_{0.35} \mathrm{Ga}_{0.65} \mathrm{As}_{0.02} \mathrm{Sb}_{0.98}$ Wav. & 400 & undoped & \\
\hline $\mathrm{Al}_{\mathrm{x}} \mathrm{Ga}_{1-\mathrm{x}} \mathrm{As}_{0.07} \mathrm{Sb}_{0.93}$ Clad. & 1200 & $\mathrm{n}$ & $3.0 \times 10^{18}$ \\
\hline \multirow[t]{2}{*}{$x=0.9-0.7, \quad 0.7-0.35$} & & & $\rightarrow 1.0 \times 10^{18}$ \\
\hline & & & $\rightarrow 5 \times 10^{17}$ \\
\hline GaSb Buffer & 1000 & $\mathrm{n}$ & $10^{18}$ \\
\hline GaSb Sub. & & $\mathrm{n}$ & \\
\hline
\end{tabular}

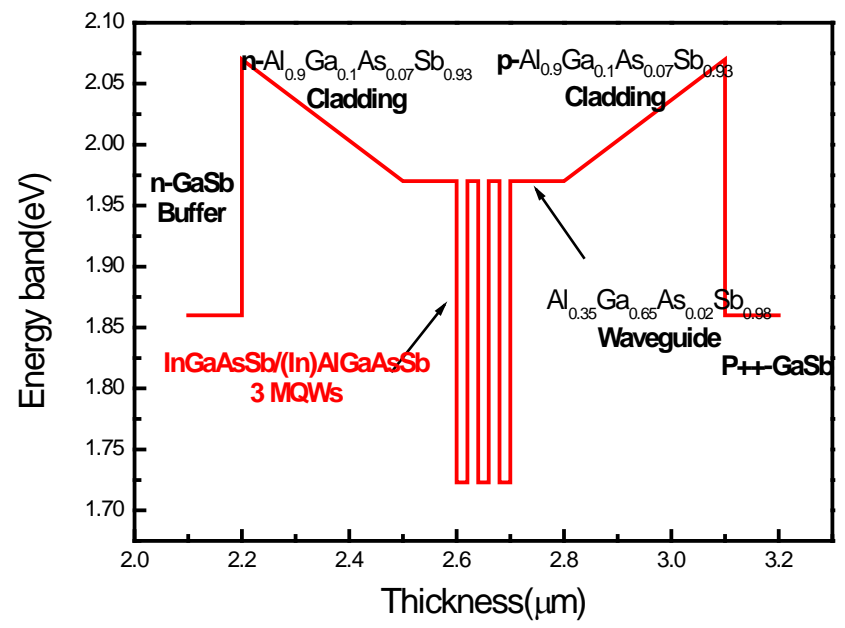

Fig. 1The energy band structure of 3QWs lasers

\section{Results and Discussion}

Fig. 1 shows the band structure of the designed 3MQWs laser, The growth of the laser material limits the $\mathrm{Al}$ content up to 0.9, using a broad waveguide design. The improvement of the $\mathrm{Al}$ composition is very important for reducing the thermal resistance and decreasing the resistance of the $\mathrm{AlGaAsSb}$, and it is also advantageous for improving the overall characteristics of the laser. Moreover, the high $\mathrm{Al}$ content makes the refractive index of the AlGaAsSb of the confinement layer decrease, The light confinement factor of the source region helps to improve the threshold characteristic and improve the performance of the laser.

The X-ray diffraction (XRD) results show that the multi-quantum well materials with good quality show the multistage diffraction peaks. 3QWs, 4QWs and 5QWs have been fabricated in this work, all of them have multi-order satellite diffraction peaks. The number of diffraction satellite peaks is not directly related to the number of quantum wells, which reflects the quality of the material. Usually, in 
the case of good epitaxial quality, the number of diffraction peaks increases with increasing the number of wells, and the half-peak width tends to narrow.

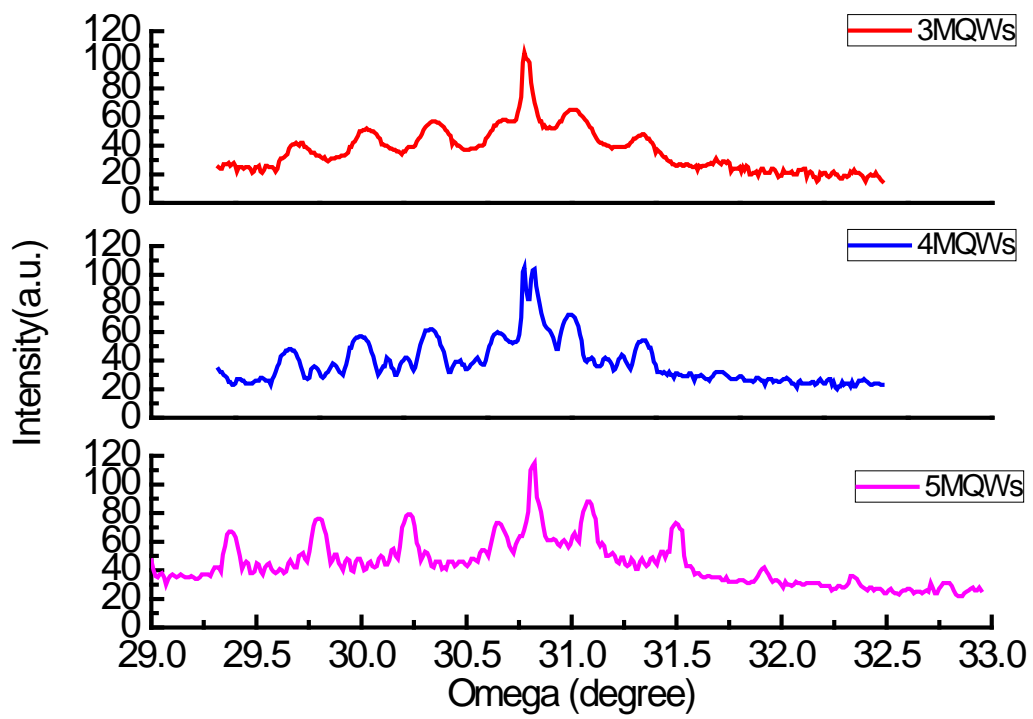

Fig. 2 XRD patterns of the materials of 3MQWs, 4MQWs and 5MQWs lasers

\section{Conclusion}

The above results indicate that the GaSb based semiconductor laser material design and growth method and device fabrication method put forwarded and adopted in this paper were very effective and conducive to the research and applications of mid-infrared semiconductor lasers.

\section{Acknowledgments}

The authors wish to express their gratitude to the projects: Jilin Province Education Department Project (No. 2015Y174), Jilin Agricultural University learning program, Jilin Provincial Department of human resources and social security Project (No. 2015Y24)for their generous support of this work.

\section{References}

[1]. D. Donetsky, S. Anikeev, G. Belenky, and S. Luryi, "Reduction of interfacial recombination in GaInAsSb/GaSb double heterostructures”,Appl. Phys. Lett., Vol.18,25(2008).

[2]. J. Tatebayashi, A. Jallipalli, M. N. Kutty, S. H. Huang, G. Balakrishnan,L. R. Dawson, and D. L. Huffakerb, "Room-temperature lasing at $1.82 \mu \mathrm{m}$ of GaInSb/AlGaSb quantum wells grown on GaAs substrates using an interfacial misfit array”, Appl. Phys. Lett.,91, 141102 (2007).

[3]. C.A.Wanga,D.A.Shiau,D.Donetsky, S. Anikeev, G. Belenky, and S. Luryi,"Extremely low surface recombination velocity in GaInAsSb/AlGaAsSb heterostructures”,Appl.Phys.Lett., 86, 101910(2005).

[4]. H.K.Choi and S.J.Eglash, "Room - temperature $\mathrm{cW}$ operation at $2.2 \mu \mathrm{m}$ of GaInAsSb/AlGaAsSb diode lasers grown by molecular beam epitaxy”, Appl.Phys. lett.59,1165(1991).

[5]. H.Lee,P.K.York,R.J.Menna,R.U.Martinelli,D.Z.Garbuzov,S.Y.Narayan, and J.C.Connolly, “Room-temperature $2.78 \mu \mathrm{m}$ AlGaAsSb/InGaAsSb quantum-well lasers”, Appl.Phys. Lett.66,1942(1995).

[6]. Kyu Hyoek Yoen, Jin Dong Song, Eun Hye Lee,et al, The growth of $\mathrm{GaSb} / \mathrm{Al}_{0.33} \mathrm{Ga}_{0.67} \mathrm{Sb}$ 
MQW on n-Silicon (100) with $\mathrm{Al}_{0.66} \mathrm{Ga}_{0.34} \mathrm{Sb}$ /AlSb SPS layers, Materials Research Bulletin, 57, 152(2014). 